\title{
Analysis of Influence and Formation for Uncoordinated Deformation in Tram Subgrade
}

\author{
Yang Cai ${ }^{1}$, Chongwei Huang ${ }^{2 *}$, Xi Chen ${ }^{1}$, Yu Sun ${ }^{2}$, Dandan $\mathrm{Guo}^{2}$ \\ ${ }^{1}$ Shanghai Urban Construction Design \& Research Institute (Group) Co., Ltd., Shanghai, 200093, P. R. of China. \\ ${ }^{2}$ Department of Transportation Engineering, University of Shanghai for Science and Technology, Shanghai, 200093, P. R. of China.
}

\begin{abstract}
Aiming at horizontal and vertical uncoordinated deformation formation in Tram Subgrade, a 3D finite element model was established, which was used to analyse the mechanical response of tram monolithic roadbed on multiple depth and width of uncoordinated deformation. The results show that the uncoordinated deformation's depth has little influence on the mechanical behavior of roadbed, and it indicates that there was remainder disengaging under the monolithic roadbed by the load of tram. On the other side, the width of uncoordinated deformation has a remarkable effect on outstanding to the horizontal tensile stress $\left(\sigma_{d y}\right)$ in the slab bottom, deflection $\left(D_{d}\right)$ on the top of slab, compressive stress $\left(\sigma_{s z}\right)$ on the top of soil, and deflection $\left(D_{s s}\right)$ on the top of soil. The deflection on the top of subgrade surface is about $1.61 \mathrm{~mm}$. Therefore, the designer's attention should be paid to avoid uncoordinated deformation width in the project, and avoid destroy of monolithic slab.
\end{abstract}

\section{Introduction}

Longitudinal uncoordinated deformation on the top of subgrade always causes the long-wave unevenness on the structure layer, which is much research on the highway. Willy Wilk et al. continuously observed the long-wave unevenness of Swiss intercontinental highway N3 and Flums-Sargans for 10 years [1]. The transverse uneven deformation of the subgrade is reflected by the uneven change of subgrade, and a "basin-shaped" settlement section was usually formed on the top of the roadbed. Qinwen Du obtained a notable "basin" after more than two years of observations on the highway [2]. As shown in Fig 1.

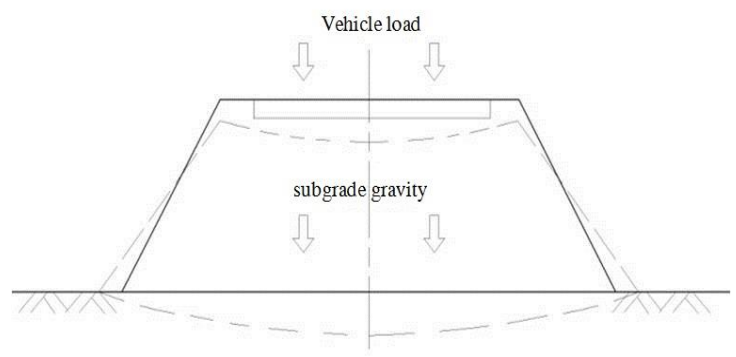

Fig 1. "Basin-shaped" settlement section diagram.

In the theoretical analysis, the "basin-shaped" settlement section was generally assumed to be parabolic or sine curve. Vos assumed that the subgrade settlement section was a sine curve, and analysed the additional stress of the concrete slab caused by the uneven settlement. It was shown that the most important effect parameter was settlement section's curvature [3]. Vos and Wilk analysed the pavement structure and discovered that the additional stress of the concrete slabs was proportional to the curvature of settlement section.

This paper established a finite element model to analyse roadbed's mechanical behavior influence by the "basin-shaped" parameters.

\section{Uncoordinated deformation calculation method}

\subsection{Finite element model}

The finite element model was constructed by using boundary condition of subgrade foundation fixing and lateral normal displacement fixing. And the authors used C3D8R unit to simulate the concrete slab, supporting layer, gravel layer, lime soil and subgrade [4]. The vehicle model uses $25 \mathrm{t}$ biaxial bogie model, material and structure models shown in Table 1. 
Tab 1. Material calculation parameters in the finite element model.

\begin{tabular}{ccccc}
\hline Layer & Material type & Thickness/m & Elastic modulus/MPa & Poisson's ratio \\
\cline { 2 - 5 } Monolithic slab & reinforced & 0.25 & $3.5 \times 104$ & 0.15 \\
Supporting layer & concrete & 0.10 & $1.5 \times 104$ & 0.20 \\
Gravel layer & gravel & 0.40 & 1500 & 0.30 \\
Lime soil layer & lime soil & 0.60 & 120 & 0.35 \\
Subgrade & soil & 7.00 & 30 & 0.40 \\
\hline
\end{tabular}

\subsection{Uncoordinated deformation calculation model}

When the foundation was rigid foundation, after the uneven settlement occurs, the monolithic slab will have the same deformation as the foundation under the action of dead weight and train load, which was equivalent to impose a certain displacement on the monolithic slab. In this case, The bending moment of the monolithic slab on the foundation deformation is:

$$
\text { - } M_{u}=E I \kappa_{u}
$$

In this formula, EI for flexural rigidity of layers, $K_{u}$ for curvature of uncoordinated deformation in foundation.

The form of the "basin shaped" subgrade was shown as follows: in the transverse section of subgrade, the settlement of subgrade center was large, while smaller on the sides, and the same as the longitudinal section. Assume that the uncoordinated deformation of subgrade distribution presents a sine curve, as shown in next formula.

$$
\text { - } y=-\delta \sin \left[\frac{\pi}{2} \times\left(\frac{x}{L}-0.5\right)\right]
$$

In this formula, $x$ for distance from road center line (or bogie wheel center line), $y$ for maximum settlement of subgrade, $\delta$ for depth of uncoordinated deformation, L for half width of uncoordinated deformation.

By assuming values of depth and width calculation parameters for different the "basin-shaped", the authors analysed the effect of uncoordinated deformation on the layers' mechanical behavior.

\section{Calculation results}

\subsection{Influence by " $\delta$,}

By changed the values of $\delta$ from 1, 2, 3, 4 to $6 \mathrm{~cm}$, and taken the values of Interlayer contact coefficient as 1.5, while kept the other calculation parameter unchanged. A finite element model was established to analyse the layers' mechanical behavior. The horizontal tensile stress $\left(\sigma_{d y}\right)$ in the slab bottom, deflection $\left(D_{d}\right)$ on the top of slab, compressive stress $\left(\sigma_{s z}\right)$ on the top of soil, and deflection $\left(D_{s s}\right)$ on the top of soil were calculated as follows [5]:
- The uncoordinated deformation's depth parameter $\delta$ had little influence on $\sigma_{d y}, D_{d}, \sigma_{s z}$ and $D_{s s}$

- On the transverse direction of the monolithic slab, the horizontal tensile stress $\left(\sigma_{d y}\right)$ concentrated obvious under the wheel track, and reaches the maximum value of $0.64 \mathrm{MPa}$.

- In the monolithic slab transverse direction, the compressive stress $\left(\sigma_{s z}\right)$ "concave" fully consistent with the shape of the "basin-shaped". Mainly because of the basin's depth was so big that there has disengaged form the supporting layer, so there has the less compressive stress in the middle of the subgrade. But on the side, the top of the subgrade's compressive stress reached the maximum value of $2.32 \mathrm{kPa}$, while subgrade deflection reached the value of $0.95 \mathrm{~mm}$.

- In the monolithic slab longitudinal direction, horizontal tensile stress $\left(\sigma_{d y}\right)$ was clearly concentrated at the bottom of the bogie track, reached the maximum value of $1.59 \mathrm{MPa}$. The slab deflection reached the maximum $8.25 \mathrm{~mm}$ under the bogie. The farther from bogie, the smaller deflection has, which was consistent with the basin shape.

- In the monolithic slab longitudinal direction, the compressive stress $\left(\sigma_{s z}\right)$ "concave" fully consistent with the shape of the "basin-shaped". Mainly because of the basin's depth was so big that there has disengaging under the supporting layer, so there was the less compressive stress in the middle of the subgrade. But on the side, the top of the subgrade's compressive stress reach the maximum at $21.44 \mathrm{kPa}$, while subgrade deflection reach $1.62 \mathrm{~mm}$.

\subsection{Influence by " $L$ ”}

By changed the values of " $\mathrm{L}$ " from $0.2 \mathrm{~L}_{0}, 0.4 \mathrm{~L}_{0}, 0.6 \mathrm{~L}_{0}$, $0.8 \mathrm{~L}_{0}$ to $\mathrm{L}_{0}$, and taken the values of Interlayer contact coefficient as 1.5, while kept the other calculation parameter unchanged [6][7]. A finite model was established to analyse the layers' mechanical behavior. As shown in Tab 2. 
Tab 2. Calculation condition.

\begin{tabular}{cccccc}
\hline Case & Case01 & Case02 & Case03 & Case04 & Case05 \\
\hline Width L & $0.2 \mathrm{~L}_{0}$ & $0.4 \mathrm{~L}_{0}$ & $0.6 \mathrm{~L}_{0}$ & $0.8 \mathrm{~L}_{0}$ & $\mathrm{~L}_{0}$ \\
\hline
\end{tabular}

The results were shown in Tab 3, Fig 2 and Fig 3:

Tab 3. The mechanical response of monolithic slab changing with basin-shaped's width.

\begin{tabular}{|c|c|c|c|c|c|c|c|c|}
\hline \multirow{3}{*}{$\begin{array}{l}\text { Basin-shaped's } \\
\text { width }\end{array}$} & \multicolumn{8}{|c|}{ Extremum } \\
\hline & \multicolumn{4}{|c|}{ Transverse direction } & \multicolumn{4}{|c|}{ Longitudinal direction } \\
\hline & $\sigma_{d y} / \mathrm{MPa}$ & $D_{d} / \mathrm{mm}$ & $\sigma_{s z} / \mathrm{kPa}$ & $D_{s s} / \mathrm{mm}$ & $\sigma_{d y} / \mathrm{MPa}$ & $\mathrm{D}_{d} / \mathrm{mm}$ & $\sigma_{s z} / \mathrm{kPa}$ & $D_{s S} / \mathrm{mm}$ \\
\hline $0.2 \mathrm{Lo}$ & 0.23 & 1.33 & 8.24 & 1.28 & 0.40 & 1.39 & 8.67 & 1.25 \\
\hline $0.4 \mathrm{Lo}$ & 0.31 & 1.41 & 9.53 & 1.30 & 0.64 & 1.78 & 12.46 & 1.24 \\
\hline $0.6 \mathrm{~L}_{0}$ & 0.39 & 1.53 & 8.72 & 1.28 & 0.89 & 3.12 & 12.71 & 1.11 \\
\hline $0.8 \mathrm{~L}_{0}$ & 0.50 & 1.84 & 5.64 & 1.19 & 1.15 & 4.46 & 22.98 & 1.45 \\
\hline $\mathrm{L}_{0}$ & 0.64 & 2.94 & 2.62 & 0.98 & 1.58 & 8.23 & 21.33 & 1.61 \\
\hline
\end{tabular}
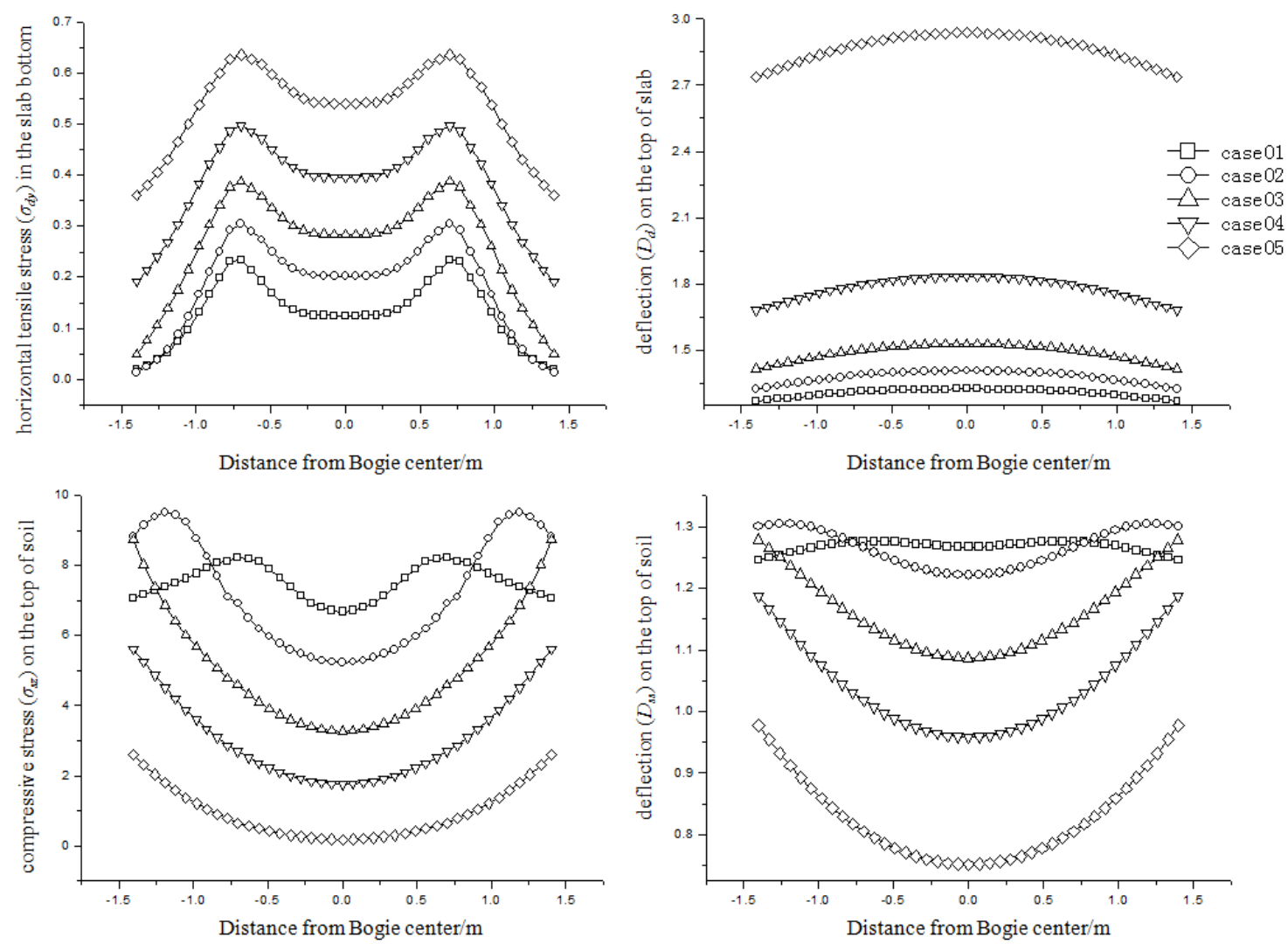

Fig 2. Monolithic slab mechanical response in the transverse direction. 

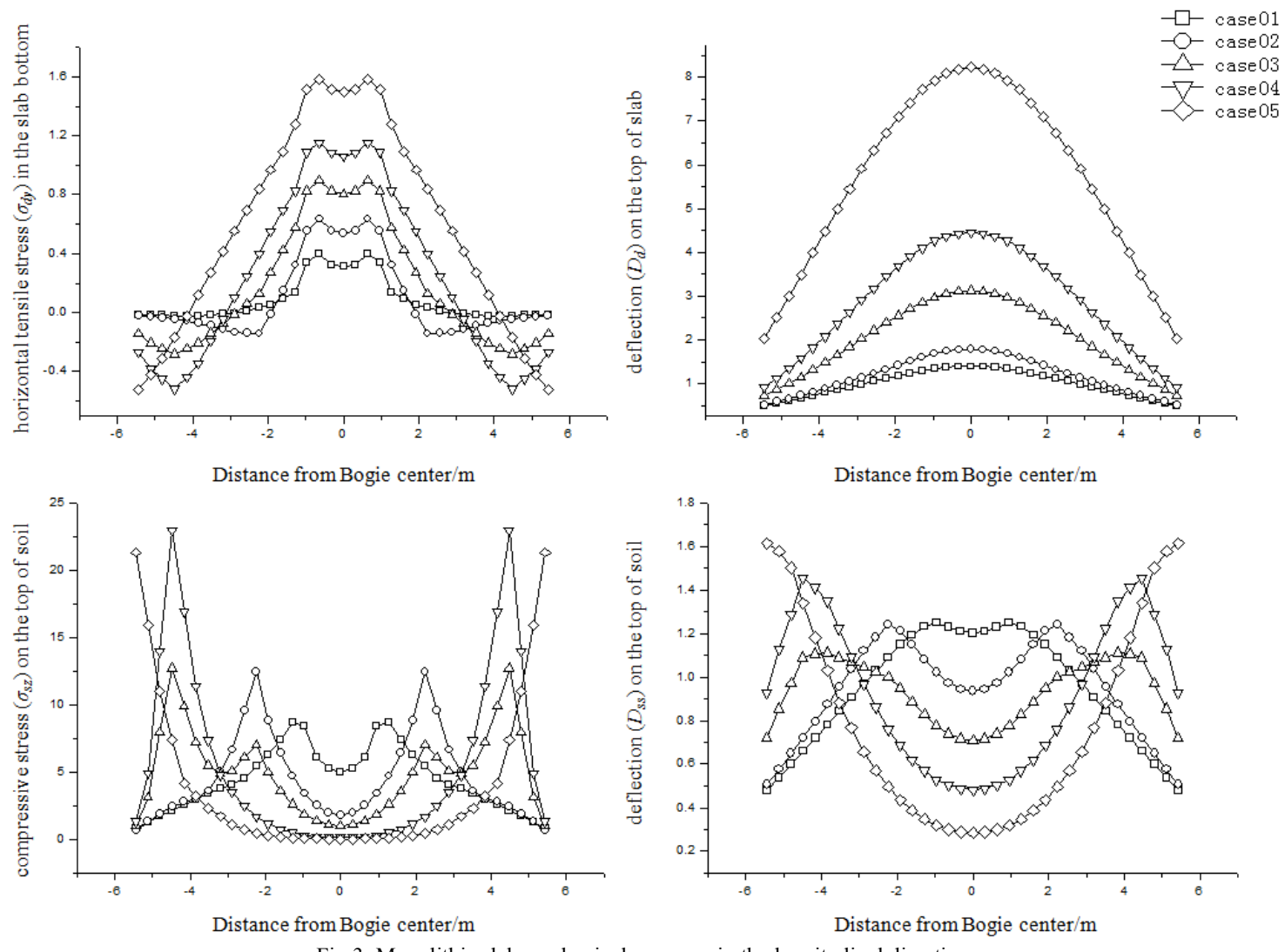

Fig 3. Monolithic slab mechanical response in the longitudinal direction.

- The uncoordinated deformation's width parameter L had a great influence on $\sigma_{d y}, D_{d}, \sigma_{s z}$ and $D_{s s}$.

- In the monolithic slab transverse direction, the horizontal tensile stress $\left(\sigma_{d y}\right)$ concentrated obvious under the wheel track. While $\mathrm{L}=\mathrm{L}_{0}$, the $\sigma_{d y}$ reached the maximum value of $0.64 \mathrm{MPa}$, and the $D_{d}$ reached the maximum value of $2.94 \mathrm{~mm}$.

- In the monolithic slab transverse direction, as the $\mathrm{L}$ increased, the $\sigma_{s z}$ decreased And the $\sigma_{s z}$ reached the maximum value of $9.53 \mathrm{kPa}$.

- In the monolithic slab longitudinal direction, the horizontal tensile stress $\left(\sigma_{d y}\right)$ concentrated obvious under the wheel track. While $\mathrm{L}=\mathrm{L}_{0}$, the $\sigma_{d y}$ reached the maximum value of $1.58 \mathrm{MPa}$, and the $D_{d}$ reached the maximum value of $8.23 \mathrm{~mm}$.

- In the monolithic slab longitudinal direction, the $\sigma_{s z}$ decreased when the $\mathrm{L}$ increased. And the $D_{s s}$ of the subgrade reached the maximum value of $1.61 \mathrm{~mm}$.

\section{Conclusion}

- The uncoordinated deformation's depth parameter $\delta$ had little influence on $\sigma_{d y}, D_{d}, \sigma_{s z}$ and $D_{s s}$.

- The uncoordinated deformation's width parameter L had a great influence on $\sigma_{d y}, D_{d}, \sigma_{s z}$ and $D_{s s}$, as the L increased, the $\sigma_{s z}$ decreased. And the $\sigma_{s z}$ reached the maximum value of
$9.53 \mathrm{kPa}$, the $D_{s s}$ of the subgrade reached the maximum value of $1.61 \mathrm{~mm}$.

- Designers should take care to avoid uncoordinated deformation width in the project and to avoid damaging the entire plate.

\section{Acknowledgment}

This research was sponsored by Shanghai Rising-Star Program (15QB1403000).

\section{References}

1. Willy Wilk. (1981) Cement concrete pavements on soft soils sensitive to differential settlements. C. Proceedings, 2nd International Conference on Concrete Pavement Design. Purdue University, U.S.A., 201-210.

2. Qinwen Du. (2002) Analysis of uneven settlement of soft soil foundation and establishment of settlement prediction system software. D. thesis, Chang'an University, Xian, China (in Chinese) .

3. Vos E. (1985) Thickness design of plain cement concrete pavements on soils sensitive to differential settlements. C. Proceedings, 3rd International Conference on Concrete Pavement Design and Rehabilitation. Purdue University, U.S.A., 245-251.

4. Chengxuan L., Wanming Z. (2001) Finite element analysis on the strength of the slab problem. J. Jounal of Rail Way Engineering Society., 1:24-26. 
5. Liang G., Mingnan M., Dongmei, W. (2007) Study on the mechanical properties of the whole ballast structure of linear motor system on the bridge. J. Railway Standard Design., 7:5-7.

6. Chunxia Li. (2005) Mechanical analysis of slab track on Soil Subgrade. D. thesis, Southwest Jiao Tong University, Chengdu, China (in Chinese).

7. Lechner B. (1996) Der Temperatur gradient als Bemessungsgrosse bei der Dimensionierung vonDicken Betondecken. D. thesis, Technische Universitat Miinchen, Miinchen, Germany., 32-56. 